\title{
Glycemic Control and Co morbidities of Patients with Type 1 and Type 2 Diabetes Referred to the National Diabetes and Endocrine Centre in Muscat, Oman
}

\author{
Noor Al Busaidi*, Prakash Shanmugam, Deepa Manoharan and Issa Al Salmi
}

National Diabetes and Endocrine Center- Royal Hospital, Muscat, Oman

\begin{abstract}
Aims: To assess the clinical profile, glycemic control associated risk factors, co morbidities and complications of patients with diabetes who were referred from primary health care facilities.

Methods: A highly specialized National Diabetes and Endocrine center (NDEC) has been established in Muscat Oman in 2013. Clinical details, glycemic control and co morbidities of all referred patients between February 2013 to January 2014 were recorded from their medical records. A total of 611 patients with type 1 and type 2 diabetes of any age and either sex were included in this study. The center receives cases requiring a better care for complicated patients with diabetes from primary, secondary and tertiary care facilities on referral base.

Results: A total of 611 patients were registered and among them 476 were with type 2 and 135 with type 1 diabetes. The mean age was 45.3 years. Nearly, $31 \%$ and $50 \%$ were overweight and obese among type 2 patients. The study highlights that above $40 \%$ patients had an $\mathrm{HbA} 1 \mathrm{c}$ of $>10 \%(85.8 \mathrm{mmol} / \mathrm{mol})$ at baseline. A greater reduction in $\mathrm{HbA} 1 \mathrm{c}(1.4 \%)$ was observed in type 2 patients whereas it was $0.5 \%$ in type 1 . Majority of type 2 had dyslipidaemia (84\%) and hypertension (62.8\%). Nephropathy was found in 40.1 and $24.4 \%$ with type 2 and type 1 diabetes whereas retinopathy was reported in 14.3 and $8.9 \%$ respectively. Female gender and longer duration of diabetes emerged as significant risk factors associated with poor glycemic control.
\end{abstract}

Conclusions: Patients with diabetes referred to a tertiary care setup in Oman had high percentage of overweight and obesity. Majority of them had poor glycemic control with associated presence of co-morbidities. Effective strategies, including education of staff and patients, are highly recommended to improve the current setup at primary care level to facilitate early detection of complications.

\section{Introduction}

Non communicable diseases have emerged as an epidemic worldwide. Globally, the prevalence of diabetes is increasing each year and has become a significant health problem. The number of adults with diabetes worldwide is expected to reach 592 million in the year 2035 from 382 million in 2013 with major increase in developing countries [1]. It has also been reported that the majority of the people with diabetes are in the age range of 40-59 years [1]. The burden of diabetes has sharply increased in Oman, as well as across the globe. The World Health Organization (WHO) has predicted 217,000 diabetic cases in the year 2025 rising from 75000 cases in 2000 [2]. Oman's 2.4 million population has undergone rapid social and economic growth in the past two decades which resulted in high rates of diabetes, obesity and hypertension in the population [3]. The huge burden of the mortality and morbidity associated with diabetes in the near future is a greater threat to the developing countries $[4,5]$.

Understanding the disease burden and profile of patients with diabetes can help in identifying the high risk group, risk factors and associated co morbidities and complications of diabetes. It also helps clinicians in working towards better glycemic control and improving quality of life for patients with diabetes. This paper aims to assess the profile of patients with diabetes (type1 and type 2), who were referred from primary health care facilities to a tertiary care center to determine their glycemic control at baseline and after a follow up period of three months and to look at associated risk factors, co morbidities and complications of diabetes.

\section{Materials and Methods}

A highly specialized National Diabetes and Endocrine Center
(NDEC) has been established in Muscat, Oman in 2013. Clinical details, glycemic control and co morbidities of all referred patients between February 2013 to January 2014 were recorded from their medical records. A total of 611 patients with type 1 and type 2 diabetes of any age and either sex were included in this study. The center receives cases requiring a better care for complicated patients with diabetes from primary, secondary and tertiary care facilities on referral base. Written informed consent was obtained from all the patients. NDEC Institutional review board approved the study.

Type 2 diabetes was defined by lack of absolute requirement for insulin, absence of ketonuria and Type 1 diabetes was defined as having absolute lack of insulin secretion [6].

The patient's demographic and anthropometric details such as height and weight were recorded and the body mass index (BMI kg/ $\mathrm{m} 2$ ) was calculated. Details on age at onset of diabetes, type of diabetes,

*Corresponding author: Noor Al Busaidi, National Diabetes and Endocrine Center Royal Hospital, P.O.box:1331, P.C:111, Muscat, Oman, Tel: 00968-24211270; Fax 24211272; E-mail: researchndec@gmail.com

Received November 17, 2015; Accepted December 18, 2015; Published December 26, 2015

Citation: Al Busaidi N, Shanmugam P, Manoharan D, Al Salmi I (2015) Glycemic Control and Co morbidities of Patients with Type 1 and Type 2 Diabetes Referred to the National Diabetes and Endocrine Centre in Muscat, Oman. J Diabetes Metab 6: 632. doi:10.4172/2155-6156.1000632

Copyright: (c) 2015 Al Busaidi N, et al. This is an open-access article distributed under the terms of the Creative Commons Attribution License, which permits unrestricted use, distribution, and reproduction in any medium, provided the original author and source are credited. 
duration of diabetes and the co morbidities were recorded. Presence of micro and macro vascular complications of diabetes was also recorded. HbA1c was measured by enzymatic method with fructosyl dipeptide oxidase using Abbott Architect c 8000 chemistry analyzer. Baseline and 3 months follow up HbA1c values were recorded. Total cholesterol was measured by cholesterol oxidase enzymatic assay, HDL cholesterol by ultra HDL assay based on accelerator selective detergent method, Triglycerides by glycerol phosphate oxidase method and LDL cholesterol was calculated by using Friedewald equation.

A BMI of $<18.5 \mathrm{~kg} / \mathrm{m}^{2}$ was considered as leanness and in the range of 18.5-24.9 as normal, 25-29.9 as overweight, 30-34.9 as class 1 obesity, 35-39.9 as class 2 obesity and above 39.9 as class 3 obesity [7]. Patients with systolic/diastolic blood pressure levels $>130 / 80 \mathrm{mmHg}$ or who were on antihypertensive medication were defined as having hypertension. Glycemic status was categorized as good glycemic control if $\mathrm{HbAlc}<7 \%(53 \mathrm{mmol} / \mathrm{mol})$ and poor glycemic control if $\mathrm{HbAlc}>7 \%(53 \mathrm{mmol} / \mathrm{mol})$ [8]. Hypercholesterolemia refers to a total cholesterol level $>5.18 \mathrm{mmol} / \mathrm{L}$, HDL cholesterol was considered as low when the level is $<1.04 \mathrm{mmol} / \mathrm{L}$ in males and $<1.3 \mathrm{mmol} / \mathrm{L}$ in females. LDL cholesterol was considered high when the level is $>$ $2.59 \mathrm{mmol} / \mathrm{L}$. Hyper triglyceridaemia refers to a level $>1.69 \mathrm{mmol} / \mathrm{L}$. Dyslipidaemia was defined as the presence of one or more of the above lipid abnormalities [9].

To assess the presence of diabetic retinopathy, the pupils are dilated using tropicamide and fundus examination was done both on slit lamp using +78 Diopter lenses and also by indirect ophthalmoscopy. Retinopathy was graded according to the International Clinical Disease Severity Scale. To assess the foot sensitivity a $10 \mathrm{~g}$ monofilament was applied to nine sites on each foot. Each site was tested three times in random order. Two or more failures per site to feel the monofilament was considered incorrect. Peripheral neuropathy was diagnosed if one or more incorrect answers were given for either foot. Nephropathy was diagnosed using the albumin to Creatinine ratio of $>30$ milligram albumin per millimole creatinine. eGFR (estimated Glomerular filtration rate) is used to stage the nephropathy. Urinary Albumin is estimated by immunoturbidimetry method and urinary creatinine by kinetic Jaffe's method.

Patients who had previous history of cardiovascular disease such as angina, myocardial infarction or any other coronary vascular event or who underwent any procedure or surgery for the same were considered having CAD (Coronary Artery Disease). Patient with history of Transient ischemic attack, infarction or hemorrhage in the brain were diagnosed as having stroke.

\section{Statistical Analysis}

The patients details have been recorded in excel sheets using double entry system, to minimize the data entry error. The excel sheet has been imported to stata ver.10, and processed for descriptive analyses and chi-square analyses. Mean and standard deviations are reported for continuous variables. Group comparisons of continuous variables were done using Students ' $t$ ' test and categorical variables were compared by Chi-square test. Binary logistic regression analysis was done to determine factors that are associated with poor glycemic control. The dependent variable was $\mathrm{HbAlc}<7 \%$ versus $>7 \%$. The independent variables were age [(years) (categorized in 10 units; $<20$ (reference), 20 $30,31-40,41-50,51-60,>60)]$, sex, BMI $\left[\left(\mathrm{kg} / \mathrm{m}^{2}\right)\right.$ (categorized as $<25$ (reference),25-29.9, 30-34.9, 35-39.9, > 40)], presence of complications (No versus Yes), duration of diabetes [(years) (categorized as $<5$ (reference), $5-10,>10$ )]. A p value of less than 0.05 was considered as statistically significant. The whole data set has been bifurcated by type of diabetes and reported accordingly.

\section{Results}

During the study period, 611 patients were referred to and treated for diabetes at NDEC in Muscat, Oman and among them 135 (22.1\%) were with type 1 diabetes and 476 (77.9\%) with type 2 diabetes. Among the total subjects, the males and females distribution was similar in both type 1 and type 2 diabetes ( $\mathrm{p}=0.923$ ).41\% of the patients with type 2 diabetes were on oral hypoglycemic drugs, $15 \%$ on insulin therapy and $44 \%$ of them were on a combination of oral hypoglycemic drugs and insulin therapy.

(Table 1) shows the demographic and body mass index details of the study patients. The mean age of the patients referred to NDEC was $45.3+16.7$ years, while as expected patients with type 2 diabetes were much older as compared to patients with type 1 diabetes. The mean age was $51.5 \pm 13.3$ and $24.2 \pm 7.9$ years respectively $(\mathrm{p}<0.0001)$. Majority of patients with type 2 diabetes were diagnosed at an age of above 40 years while age at onset was less than 30 years for type 1 diabetes.

Mean BMI was significantly higher among patients with type 2 diabetes as compared to patients with type 1 diabetes ( $30.5 \pm 7.1$ Vs 24.4 $\pm 5.2)(\mathrm{p}<0.0001) .9 .6 \%$ of type1 patients had lean BMI. The prevalence of overweight and obesity among type 2 patients were $31.3 \%$ and $50 \%$ respectively. Mean duration of diabetes was similar both in type 1 and type 2 patients ( $\mathrm{p}=0.556$ ). Nearly $40 \%$ of type 1 patients had duration of diabetes of less than 5 years whereas majority of type 2 patients had longer duration of diabetes of more than 5 years.

(Table 2) shows the glycemic status of patients at baseline and follow

\begin{tabular}{|c|c|c|c|c|c|}
\hline \multicolumn{2}{|c|}{ Characteristics } & $\begin{array}{l}\text { Type }-1 \\
\mathrm{~N}=135\end{array}$ & $\begin{array}{l}\text { Type }-2 \\
N=476\end{array}$ & $\begin{array}{l}\text { Chi- } \\
\text { square }\end{array}$ & $P$ value \\
\hline \multirow[t]{2}{*}{ Gender } & $\begin{array}{c}\text { Female } \\
(\mathrm{N}=344) \\
(56 \%)\end{array}$ & 77 (57.0\%) & 267 (56\%) & & \\
\hline & $\begin{array}{c}\text { Male }(\mathrm{N}=267) \\
(44 \%)\end{array}$ & $58(43 \%)$ & 209 (44\%) & 0.009 & 0.923 \\
\hline \multicolumn{2}{|c|}{ Age years (Mean $\pm S D$ ) } & $24.2 \pm 7.9$ & $51.5 \pm 13.3$ & & $<0.0001$ \\
\hline \multirow[t]{6}{*}{$\begin{array}{c}\text { Age } \\
\text { categories (years) }\end{array}$} & less than 20 & $45(33.3 \%)$ & $6(1.3 \%)$ & & \\
\hline & $20-30$ & 70 (51.9\%) & $21(4.4 \%)$ & & \\
\hline & $31-40$ & $13(9.6 \%)$ & $77(16.2 \%)$ & & \\
\hline & $41-50$ & $5(3.7 \%)$ & $116(24.4 \%)$ & & \\
\hline & $51-60$ & $2(1.5 \%)$ & $132(27.7 \%)$ & & \\
\hline & $>60$ & - & $124(26.1 \%)$ & 382 & $<0.0001$ \\
\hline \multicolumn{2}{|c|}{$\mathrm{BMI}\left(\mathrm{kg} / \mathrm{m}^{2}\right)($ Mean $\pm \mathrm{SD})$} & $24.4 \pm 5.2$ & $30.5 \pm 7.1$ & & $<0.0001$ \\
\hline \multirow[t]{6}{*}{$\begin{array}{l}\mathrm{BMI}\left(\mathrm{kg} / \mathrm{m}^{2}\right) \\
\text { categories }\end{array}$} & $\begin{array}{l}\text { Less than } \\
\quad 18.5\end{array}$ & $13(9.6 \%)$ & $6(1.3 \%)$ & & \\
\hline & $18.5-24.9$ & $59(43.7 \%)$ & $84(17.6 \%)$ & & \\
\hline & $25-29.9$ & $40(29.6 \%)$ & $149(31.3 \%)$ & & \\
\hline & $30-34.9$ & $18(13.3 \%)$ & $125(26.3 \%)$ & & \\
\hline & $35-39.9$ & $4(3.0 \%)$ & $66(13.9 \%)$ & & \\
\hline & $>40$ & $1(0.7 \%)$ & $46(9.7 \%)$ & 83.6 & $<0.0001$ \\
\hline $\begin{array}{l}\text { Duration of DM } \\
\text { (years) (Mean } \pm \\
\text { SD) }\end{array}$ & & $8.7 \pm 7.5$ & $9.1 \pm 6.8$ & & 0.556 \\
\hline \multirow[t]{3}{*}{$\begin{array}{l}\text { Duration of DM } \\
\text { categories }\end{array}$} & Less than 5 & $55(40.7 \%)$ & $139(29.2 \%)$ & & \\
\hline & $5-10$ & $38(28.1 \%)$ & $183(38.4 \%)$ & & \\
\hline & $>10$ & $42(31.1 \%)$ & $154(32.4 \%)$ & 7.5 & 0.023 \\
\hline
\end{tabular}

Table 1: Demographic and BMI details of patients with type 1 and type 2 diabetes. 
up visit. $85 \%$ of type 1 patients came for review whereas only $62 \%$ of type 2 patients came for follow up. The results showed that about $40 \%$ of both type 1 and type 2 patients had uncontrolled diabetes (HbAlc $>10 \% ; 85.8 \mathrm{mmol} / \mathrm{mol}$ ) at baseline visit with a mean HbAlc of nearly $10 \%$ in both the group of patients indicating poor glycemic control. At follow up visit, only $20 \%$ of type 2 patients had poor glycemic control which revealed that there was an improvement in majority of patients at review visit. There was not much difference in the glycemic control at baseline and review visit among type 1 patients. (10.3 \pm 2.9 vs $9.8 \pm 2.9$; $\mathrm{p}=0.179)$. A greater reduction in $\mathrm{HbAlc}$ was observed in type 2 patients $(9.7 \pm 2.8$ vs $8.3 \pm 2.4 ; \mathrm{p}<0.0001)$. There was $1.4 \%$ reduction in $\mathrm{HbAlc}$ in type 2 patients whereas it was $0.5 \%$ in type 1 patients.

(Table 3) shows the treatment details and presence of micro and macro vascular complications of diabetes. It was noted that most of the patients with type 2 diabetes (83\%) have undergone lipid treatment, whereas a lesser percentage of patients with type 1 diabetes had dyslipidaemia (40\%) and $39.3 \%$ were on lipid treatment. Nearly $63 \%$ had hypertension in type 2 and $7.4 \%$ in type 1 patients $(\mathrm{p}<0.0001)$. Diabetic nephropathy was highly prevalent among type 2 patients ( $40.1 \%$ vs $24.4 ; \mathrm{p}=0.001$ ). The prevalence of retinopathy among type 2 patients was $14.3 \%$ and $8.9 \%$ in type 1 patients. CAD, stroke and foot infection were present in $9.7 \%, 2.5 \%$ and $0.6 \%$ respectively in type 2 patients.

(Table 4) shows the results of binary logistic regression analysis which revealed that female gender with odds ratio of $1.8 ;(\mathrm{p}=0.026)$, duration of diabetes categories $5-10$ and $>10$ years with odds ratio of 2.3; $(\mathrm{p}=0.009)$ and $2.0 ;(\mathrm{p}=0.036)$ respectively were significantly associated with poor glycemic control at baseline among patients with diabetes.

\section{Discussion}

This study highlights that diabetic patients referred from primary and secondary care health centers to a multidisciplinary NDEC in Muscat, Oman had high rates of overweight and obesity, poor glycemic

\begin{tabular}{|c|c|c|}
\hline Characteristics & $\begin{array}{l}\text { Type } 1 \text { patients } \\
\text { (N=133) } \\
(\%)\end{array}$ & $\begin{array}{l}\text { Type } 2 \text { patients } \\
\text { (N = 470) } \\
(\%)\end{array}$ \\
\hline \multicolumn{3}{|l|}{$\begin{array}{l}\mathrm{HbA} 1 \mathrm{c} \%(\mathrm{mmol} / \mathrm{mol}) \\
\text { details at base line }\end{array}$} \\
\hline$<=7(53)$ & 10.5 & 17.5 \\
\hline $7.1-8(54.1-63.9)$ & 12.0 & 14.0 \\
\hline $8.1-9(65-74.9)$ & 15.0 & 15.1 \\
\hline $9.1-10(76-85.8)$ & 15.0 & 13.4 \\
\hline$>10(>85.8)$ & 47.4 & 40.0 \\
\hline \multirow[t]{2}{*}{ Mean + SD } & $10.3+2.9$ & $9.7+2.8^{*}$ \\
\hline & Type $1(\mathrm{~N}=113)$ & Type $2(\mathrm{~N}=292)$ \\
\hline \multicolumn{3}{|l|}{$\begin{array}{c}\mathrm{HbA1c} \\
\%(\mathrm{mmol} / \mathrm{mol}) \text { details at } \\
\text { review }\end{array}$} \\
\hline$<=7(53)$ & 13.3 & 33.9 \\
\hline $7.1-8(54.1-63.9)$ & 16.8 & 22.6 \\
\hline $8.1-9(65-74.9)$ & 17.7 & 12.3 \\
\hline $9.1-10(76-85.8)$ & 15.0 & 11.0 \\
\hline$>10(>85.8)$ & 37.2 & 20.2 \\
\hline Mean+SD & $9.8+2.9$ & $8.3+2.4^{* *}$ \\
\hline
\end{tabular}

Type1 versus Type2 patients; ${ }^{*} p=0.031,{ }^{* *} p<0.0001$.

Table 2: Glycemic status of type 1 and type 2 patients at baseline and at review visit

\begin{tabular}{|c|c|c|c|c|}
\hline \multicolumn{2}{|c|}{$\begin{array}{c}\text { Treatment and } \\
\text { Complications }\end{array}$} & $\begin{array}{c}\text { Type 1 (N=135) } \\
\mathbf{n}(\%)\end{array}$ & $\begin{array}{c}\text { Type 2 (N = 476) } \\
\mathbf{n}(\%)\end{array}$ & P value \\
\hline Lipid Treatment & Yes & $53(39.3)$ & $395(82.9)$ & $<0.001$ \\
\hline Retinopathy & Yes & $12(8.9)$ & $68(14.3)$ & 0.135 \\
\hline Nephropathy & Yes & $33(24.4)$ & $191(40.1)$ & 0.001 \\
\hline Dyslipidaemia & Yes & $54(40.0)$ & $400(84.0)$ & $<0.0001$ \\
\hline Hypertension & Yes & $10(7.4)$ & $299(62.8)$ & $<0.0001$ \\
\hline CAD & Yes & --- & $46(9.7)$ & \\
\hline Stroke & Yes & --- & $12(2.5)$ & \\
\hline Foot infection & Yes & --- & $3(0.6)$ & \\
\hline
\end{tabular}

Table 3: Status of treatment and presence of micro and macro vascular complications.

\begin{tabular}{|c|c|c|c|c|}
\hline $\begin{array}{c}\text { Significant } \\
\text { variables }\end{array}$ & $\boldsymbol{\beta}$ & SE $\boldsymbol{\beta}$ & $\begin{array}{c}\text { Odds Ratio } \\
\text { (95\% confidence interval) }\end{array}$ & P value \\
\hline $\begin{array}{c}\text { BMI (kg/m } \mathbf{2}) \\
\mathbf{2} \mathbf{2 5}(\text { reference) } \\
\mathbf{( 3 0 - 3 4 . 9 )}\end{array}$ & 0.706 & 0.367 & $0.5(0.24-1.0)$ & 0.054 \\
\hline $\begin{array}{c}\text { Gender (female) } \\
\text { Duration of DM } \\
\text { ( years ) }\end{array}$ & 0.574 & 0.257 & $1.8(1.1-2.94)$ & 0.026 \\
\hline $\begin{array}{c}\text { (reference) } \\
\text { (5-10) }\end{array}$ & 0.844 & 0.325 & $2.3(1.2-4.4)$ & 0.009 \\
\hline$>\mathbf{1 0}$ & 0.715 & 0.341 & $2.0(1.0-3.9)$ & 0.036 \\
\hline
\end{tabular}

Non-significant variables: Age categories, BMI categories (25-29.9), (35-39.9), $(>40)$, presence of complications.

Table 4: Results of binary logistic regression analysis: Dependent variable $(\mathrm{HbA} 1 \mathrm{c}$ $<7 \% ; 53 \mathrm{mmol} / \mathrm{mol}$ vs $>7 \% ; 53 \mathrm{mmol} / \mathrm{mol}$ )

control and high rates of micro and macro vascular complications. Female gender and duration of diabetes emerged as significant factors for poor glycemic control.

The onset of complications of diabetes is directly associated with the duration of the disease and poor glycemic control but the long asymptomatic stage of diabetes may likely to develop complications even at the time of diagnosis [10,11]. A review article has reported approximately one half of the patients diagnosed with type 2 diabetes dies prematurely due to cardiovascular diseases, while $10 \%$ die due to renal failure [12]. High $\mathrm{HbA}_{1} \mathrm{c}$ levels are associated with an increased risk of mortality and development of micro and macro vascular complications of diabetes $[13,14]$. Complications cause huge burden on health system due to cost involved in the management of diabetes. A hospital based cross-sectional study in Oman reported $14.4 \%$ of diabetic retinopathy, with men having significantly higher rates than women, and it was significantly high among those with longer duration of diabetes [15]. Considering the huge cost involved in the management of diabetes and its complications, undertaking early screening for diabetes and its complications remains an important cost effective strategy.

Our population, like all developing nations, is experiencing rapid socio economic transition with an increase in the consumption of high fat calorie dense food, refined sugar and with increased rates of smoking [16]. A description of the profile of patients with diabetes seen in a tertiary care center revealed that a significantly higher proportion of patients were overweight and obese. Nearly half of the patients registered had an $\mathrm{HbA}_{1} \mathrm{c}$ of more than $85.8 \mathrm{mmol} / \mathrm{mol}$ at baseline visit indicating poor glycemic control. A large proportion of the patients had the presence of micro and macro vascular complications of diabetes. However, a greater reduction in $\mathrm{HbA}_{1} \mathrm{c}$ was noted among patients with type 2 diabetes at review after 3 months with not much improvement in patients with type 1 diabetes. This difference in $\mathrm{HbAlc}$ 
reduction between type 1 and type 2 diabetic patients is due to the fact that there is absolute lack of insulin and could be due to the lack of strict adherence to medication, diet and monitoring in type 1 diabetes patients.

The reported prevalence of obesity was significantly higher in this study. Around $31 \%$ and $50 \%$ of patients with type 2 diabetes were overweight and obese respectively. In a previous report, it was shown that one fifth of the adult populations are obese with higher rates in men than in women [16]. The present study findings highlights the urgent need of all concerned authorities to work, focus and amalgamate all their efforts, directed towards weight reduction in the high risk group by appropriate life style interventions.

The mean age of patients with type 2 diabetes was $51.5 \pm 13.3$ years in this study. Development of diabetes at this productive age is an important issue as these patients are at higher risk of developing complications due to long exposure to hyperglycemia. Another important finding was that nearly half of the patients had an $\mathrm{HbA}_{1} \mathrm{c}$ of more than $85.8 \mathrm{mmol} / \mathrm{mol}$ at base line visit indicating severe hyperglycemia. However, at review visit after three months, an improvement in $\mathrm{HbA}_{1} \mathrm{c}$ was seen in type 2 patients whereas not much improvement was noted in type 1 patients. Nearly $1.4 \%$ reduction in $\mathrm{HbA}_{1} \mathrm{c}$ was noted in type 2 with only $0.5 \%$ in type 1 patients. Further studies are needed to explain the differences in long term glycemic control among different types of diabetes. A very recent study in Zimbabwean population also reported the differences in long-term glycemic control with $54 \%$ of type 1 patients having poor control compared to $24 \%$ in type 2 diabetes [17].

Several studies have demonstrated the potential benefits of improving glycemic control to achieve $\mathrm{HbA}_{1} \mathrm{c}$ targets in patients with type 2 diabetes $[18,19]$. For each one percent reduction in $\mathrm{HbA}_{1} \mathrm{c}$ there is a relative risk reduction of 21 percent for any diabetes-related end point, $21 \%$ for diabetes-related deaths, $14 \%$ relative risk reduction for myocardial infarction and $37 \%$ for micro vascular complications [20]. A higher percentage of patients had presence of both micro and macro vascular complications in this study. These results highlight the need for structured care provided by competent health care staff. Attention is needed for provision of facilities for doing regular physical activity and also appropriate resources. Certain challenges such as patient related factors in diet control and physical activity should be considered while formulating interventions.

In the current study, female gender emerged as a significant risk factor for poor glycemic control at baseline. Another risk factor associated with poor glycemic control was longer duration of diabetes. The results highlight that an educational program for female gender that emphasizes diabetes self-care management behaviors would be of great benefit in maintaining good glycemic control. The odds ratio for duration of diabetes was above 2.0 in this study. The finding is consistent with that reported in Jordanian population [21].

The main limitation of this study was that the results were based on hospital data and are not a representative of entire population of the country. Moreover, comparison of these results with data from general population would have highlighted the differences and thrown more light but we do not have data collected from general population. However, the results of this study highlight the need for early screening of diabetes and its complications, correction of hyperglycemia and dyslipidaemia. Also, it calls for a fully integrated care for people with dysglycaemia in abide to curtail the development of complications and ameliorate their progression.
In conclusion, patients with diabetes referred to a tertiary care center had high rates of overweight and obesity. Female gender and longer duration of diabetes are significant risk factors for poor glycemic control. Presence of co morbidities was high among the patients referred from primary health care centers. This could be due to late referral, reasons related to organizational, professional or patient causes or other reasons related to culture and social commitments. Strengthening the health care system for a standard care delivery for diabetes and its complications will resolve the burden of diabetes. Effective strategies are highly recommended to improve the current set up at primary care level to focus on education and motivation on behavioral changes and also to facilitate early detection of complications.

\section{Acknowledgements}

We thank all our patients and all staffs at National diabetes and Endocrine Center for their cooperation and support. We would particularly like to thank Dr. Fatihma Pambinezhuth, Dr. Shafiq Yusuff, Dr. Suzeth A Encarnado, Mr. Batt for their contribution in data collection.

\section{References}

1. International Diabetes Federation (2013) International Diabetes Federation Atlas. (6 $6^{\text {th }}$ edn), International Diabetes Federation, Brussels, Belgium.

2. Shookri Al, Khor GL, Chan YM, Loke SC, Al-Maskari M (2011) Type 2 diabetes in the Sultanate of Oman. Malaysian Journal of Nutrition 17: 129-141.

3. Al-Moosa S, Allin S, Jemiai N, Al-Lawati J, Mossialos E (2006) Diabetes and urbanization in the Omani population: an analysis of national survey data Popul Health Metr 4: 5

4. King H, Aubert RE, Herman WH (1998) Global burden of diabetes, 1995-2025 Prevalence, numerical estimates and projections. Diabetes care 21: 1414-31.

5. Hossain P, Kawar B, El Nahas M (2007) Obesity and diabetes in the developing world--a growing challenge. N Engl J Med 356: 213-215.

6. American Diabetes Association (2008) Diagnosis and classification of Diabetes Mellitus 31: S55-S60.

7. [No authors listed] (1995) Physical status: the use and interpretation of anthropometry. Report of a WHO Expert Committee. World Health Organ Tech Rep Ser 854: 1-452.

8. American Diabetes Association (2007) Standards of medical care in diabetes-2007 (position statement) Diabetes care 30: S4-S41.

9. American Diabetes Association (2004) Dyslipidemia management in adult with diabetes. Diabetes care 24: 68-71

10. Harris MI, Klein R, Welborn TA, Knuiman MW (1992) Onset of NIDDM occurs at least 4-7 yr before clinical diagnosis. Diabetes Care 15: 815-819.

11. Spijkerman AM, Dekker JM, Nijpels G, Adriaanse MC, Kostense PJ, et al. (2003) Micro vascular complications at time of diagnosis of type 2 diabetes are similar among diabetic patients detected by targeted screening and patients newly diagnosed in general practice. Diabetes care 26: 2604-2608.

12. van Dieren S, Beulens JW, van der Schouw YT, Grobbee DE, Neal B (2010) The global burden of diabetes and its complications: an emerging pandemic Eur J Cardiovasc Prev Rehabil 17 Suppl 1: S3-8.

13. Gertein HC, Swedberg K, Carlsson J, McMurray JJ, Michelson EL, et al. (2008) The hemoglobin A1c level as a progressive risk factor for cardiovascular death, hospitalization for heart failure, or death in patients with chronic heart failure: an analysis of the candesartan in heart failure; Assessment of reduction in mortality and morbidity (CHARM) program. Archives of Internal Medicine 168 1699-1704.

14. Hemmingsen B, Lundd SS, Gluud C, Vaag A et al. (2013) Targeting intensive glycemic control versus targeting conventional glycemic control for type 2 diabetes mellitus. Cochrane diabetes review 11: 11-CD008143.

15. Khandekar R, Al Lawatii J, Mohammed AJ, Al Raisi A (2003) Diabetic retinopathy in Oman: a hospital based study. Br J Ophthalmol 87: 1061-1064.

16. Al-Lawati J, Jousilahti $P$ (2004) Prevalence and 10 years secular trend of obesity in Oman. Saudi Medical Journal 25: 346-351.

17. Chako KZ, Phillipo H, Mafuratidze E, Zhou DT (2014) Significant differences 
Citation: Al Busaidi N, Shanmugam P, Manoharan D, Al Salmi I (2015) Glycemic Control and Co morbidities of Patients with Type 1 and Type 2 Diabetes Referred to the National Diabetes and Endocrine Centre in Muscat, Oman. J Diabetes Metab 6: 632. doi:10.4172/2155-6156.1000632

Page 5 of 5

in the prevalence of elevated $\mathrm{HbA} 1 \mathrm{c}$ levels for type 1 and type 2 diabetics attending the Parirenyatwa Diabetic Clinic in Harare, Zimbabwe. Chinese Journal of Biology.

18. UK Prospective Diabetes Study (UKPDS) Group (1998) Effect of intensive blood glucose control with metformin on complications in overweight patients with type 2 diabetes (UKPDS34). Lancet 352: 854-865.

19. Holman RR, Paul SK, Bethel MA, Matthews DR, Neil HA (2008) 10-year followup of intensive glucose control in type 2 diabetes. N Engl J Med 359: 1577 1589.
20. Stratton IM, Adler AI, Neil HA, Matthews DR, Manley SE, et al. (2000) Association of glycemia with macro vascular and micro vascular complications of type 2 diabetes (UKPDS35). British Medical Journal 321: 405-412.

21. Khattab M, Khader YS, Al-Khawaldeh A, Ajlouni K (2010) Factors associated with poor glycemic control among patients with type 2 diabetes. J Diabetes Complications 24: 84-89. 